\title{
Negative cytology preceding cervical cancer: Causes and prevention
}

\author{
J H Robertson, B Woodend
}

\begin{abstract}
Aim-To assess the validity of negative cervical smear reports in women who subsequently developed cervical cancer; and to determine means of improving the screening process.

Methods-One hundred and forty cervical smears, initially reported as negative from 103 women, and taken up to 12 years before diagnosis of cervical cancer, were reviewed.

Results-Ninety two smears contained dyskaryotic cells. Analysis showed that these smears formed several well defined patterns. False negative reports were likely to occur if fragments of neoplastic tissue rather than dissociated dyskaryotic cells were present or if the smear contained few dyskaryotic cells. Screening fatigue appeared to be a factor in others. It was also considered important that smears contained cells from the endocervix. These were deficient in $64 \%$ of the 47 smears confirmed as negative on review and in $69 \%$ of smears containing only a few dyskaryotic cells.

Conclusions-Current methods of quality assurance will not remedy these defects in the screening process. It is the responsibility of laboratories to identify sources of poor smears and liaise with smear takers to ensure an improvement in quality. Assessment of the quality of smears received by a laboratory should become an important part of audit. Staff training should place more emphasis on the interpretation of "microbiopsies". The adoption of a quick scanning technique before conventional screening would probably also substantially reduce false negative results.
\end{abstract}

(F Clin Pathol 1993;46:700-702)

It has long been recognised that there is a very appreciable screening error in the laboratory examination of cervical smears. ${ }^{1-3}$ This has led most laboratories to expend much time and effort on quality control measures to improve the accuracy of their reporting. Recently we had an opportunity to review smears which had been reported as negative from women who subsequently developed cervical cancer. The cytological changes in these smears will be described in another report. The purpose of the present study was to identify causes of failure in the screening process and to relate these to present methods of laboratory practice and quality control.

\section{Methods}

From a previous survey of the incidence of invasive cervical cancer in Northern Ireland from $1965-89,{ }^{4}$ we identified a number of patients who presented with the disease and who had previous cervical smears reported as normal. Patients with microinvasive disease were excluded. Details of the negative smears taken before diagnosis of the carcinoma were obtained from the patients' hospital and general practitioner records. A total of 140 smears from 103 patients aged 27 to 74 years taken over a period of up to 12 years before diagnosis of the carcinoma were available for review. Of the 103 patients, 83 later developed squamous carcinoma and 20 adenocarcinoma. The smears had been reported by seven laboratories in Northern Ireland, England, and Scotland, the largest number originating from this laboratory. Almost all the smears were obtained and reviewed by the authors, some were re-examined by the local pathologist.

The authors reviewed the smears independently. Initially they were scanned, as described by Baker and Melcher, ${ }^{5}$ to determine whether any positive smears could be detected by these means. They were then examined in a conventional manner for evidence of dyskaryosis. In those containing dyskaryotic cells the number was estimated according to the following criteria: (a) fewrequiring careful examination for detection, could well be missed on routine screening; (b) moderate - should be detected by screening; (c) many-abnormal cells could be detected on initial quick scanning of the smear.

Smears in which the main evidence of abnormality was the presence of fragments of dysplastic epithelium with few dissociated dyskaryotic cells were also noted, as were those in which blood, inflammatory, or postmenopausal changes were sufficiently noticeable to obscure dyskaryosis.

Smears which were negative or contained few dyskaryotic cells on review were assessed for the presence of an endocervical component. This was considered to be absent if neither columnar nor metaplastic cells were present or if only one or two possible small clusters of these cells were seen.

A high degree of agreement was achieved by the authors in the independent review. 
Figure 1 Results on review of 139 smears initially reported as negative, from 102 patients who subsequently were found to have either squamous or adenocarcinoma of the cervix.

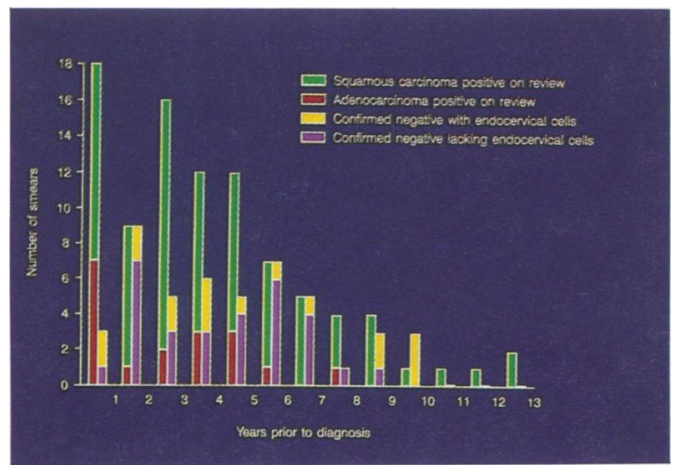

Figure 2 (A)

"Microbiopsy" of with normal columnar epithelial fragment seen during screening. adenocarcinoma compared
Figure 2 (B) Severely dysplastic squamous epithelium (left) and squamous metaplastic epithelium (right).

Distinction is made more difficult by inflammatory changes.
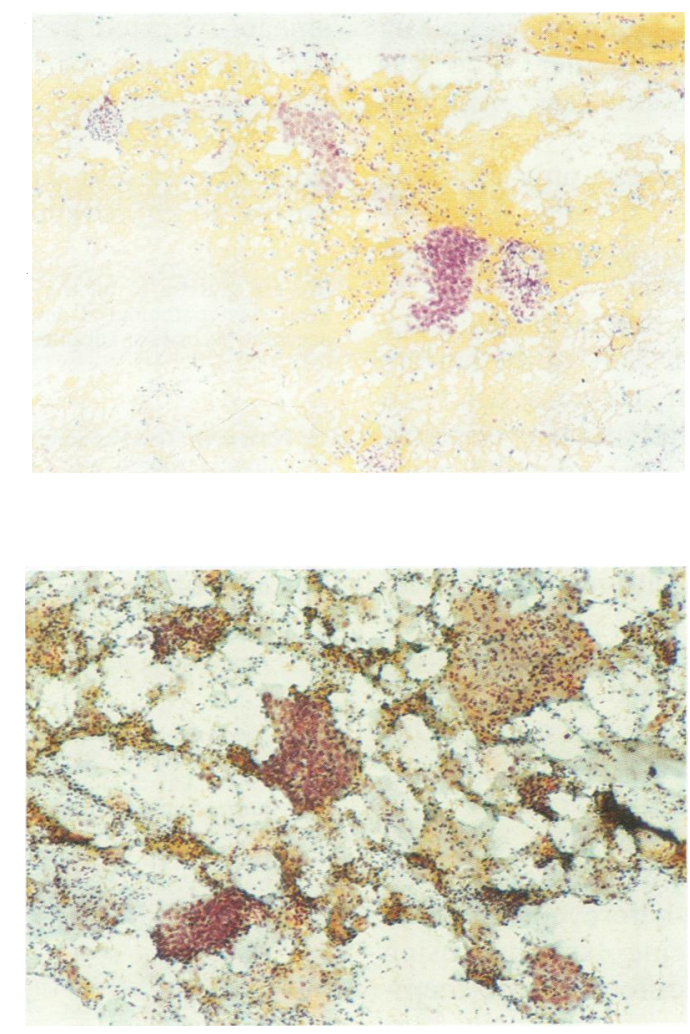

Figure 3 Percentage distribution of smear patterns from patients who developed squamous or adenocarcinoma. The smear pattern is related to the probable cause of false negative report and quality of smear.

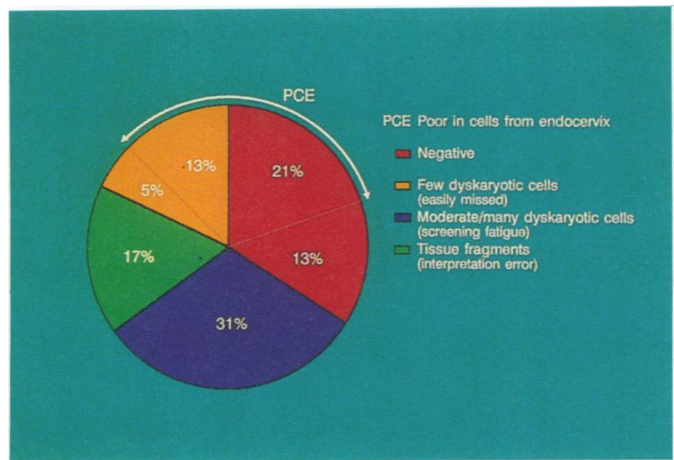

This was particularly true for smears containing abnormal squamous cells. Smears from patients with adenocarcinoma presented more difficulty and it was sometimes necessary to compare the biopsy specimen with the smear.

\section{Results}

One smear which was unsuitable because of severe inflammatory changes was excluded from further analysis. Figure 1 shows the findings on review of the remaining 139 smears from 102 patients and the interval between the smears and the diagnosis of carcinoma. Forty seven smears (39 preceding squamous and eight preceding adenocarcinoma) were confirmed as being negative, but $30(64 \%)$ of these lacked an appreciable endocervical component.

The remaining 92 smears contained dyskaryotic cells, 74 of which were squamous and 18 of columnar origin. Analysis of these smears showed several quite well defined patterns. In 26 smears the abnormal cells were few in number, and in about a third of these so few abnormal cells were present that there seemed little prospect of detection by normal screening methods. In seven the few dyskaryotic cells present were more difficult to distinguish because of inflammatory or postmenopausal changes in the smear. Of these 26 smears containing few neoplastic cells, 18 $(69 \%)$ were deficient in endocervical cells.

In 24 of the 92 positive smears the main indication of epithelial abnormality was the presence of fragments of severely dysplastic epithelium (figs $2 \mathrm{~A}$ and B). Recognition of the smear as being abnormal depended largely on interpretation of these fragments as only a small number of dissociated dyskaryotic cells were present. This smear pattern occurred in smears preceding both squamous and adenocarcinoma but was more common in the latter, being associated with almost half the false negative reports in these patients. In more than half these cases the epithelial fragments were sufficiently numerous that, provided their clinical importance was appreciated, the smear was readily identifiable as positive on scanning.

Of the remaining 42 smears found to be positive, all contained dissociated dyskaryotic cells in at least moderate numbers. In 15 many dyskaryotic cells were present so that these smears were also detected as positive by the reviewers on their preliminary quick scan.

\section{Discussion}

Although it is recognised that false negative cervical smears are not rare, the definition of "false negative" has varied among studies and many have not entailed the re-examination of smears. ${ }^{6}$ By analysing the smear patterns from our patients we attempted to determine why the screening process did not give warning of an impending carcinoma and to seek ways to improve the effectiveness of cervical screening.

This was a retrospective study the purpose of which was known to local pathologists, making it difficult to arrange for an external review of the smears. They were examined by the authors independently, however, and the results of the smear analysis are summarised in fig 3. Smears lacking an endocervical component are unreliable. Each year about $20 \%$ of smears received by this laboratory lack columnar or metaplastic cells from the endo- 
cervix. In contrast, of the smears confirmed as negative and those containing few dyskaryotic cells, almost two thirds were deficient in an endocervical component.

In $17 \%$ of the smears reviewed the epithelial abnormality was mainly evident as tissue fragments. As has been noted by others, ${ }^{7}$ training programmes and text-books have concentrated almost exclusively on the cytology of dissociated cells so that staff have paid little attention to the identification of tissue fragments during screening. Although attention has been drawn to the importance of these microbiopsies in the diagnosis of adenocarcinoma, ${ }^{8}$ we feel that it is still not sufficiently widely taught that squamous neoplasia may also present in this manner. Too frequently dysplastic fragments are misinterpreted as reflecting squamous metaplasia. Dysplastic epithelium, evident only as tissue fragments removed by the spatula, also indicates the importance of obtaining smears which sample the endocervix.

Screening fatigue was the probable cause of false negative results in $31 \%$ of the smears examined. The tedium of screening has been well described by Rylander ${ }^{9}$ and was certainly exacerbated by the work overload which most laboratories have experienced. We feel that in such circumstances fatigue can result in smears being screened without any critical analysis being made, the screener being unaware of this at the end of the examination. Double screening of smears has been considered a remedy but would be costly. Our results support the value of the rapid scanning technique described by Baker and Melcher, ${ }^{5}$ and we consider that scanning would probably be effective if incorporated into laboratory practice before conventional screening, each smear being examined using the two techniques by different staff members.
It seems unlikely that current methods of quality control will prevent many of these deficiencies from occurring in screening practice. Proficiency testing in a formal setting does not reproduce the tedium of screening and prevent errors from this cause. Quality control measures should also place more emphasis on the interpretation of microbiopsies than occurs at present. If the usefulness of rapid scanning is confirmed it would be important to test ability to perform this technique. The reliability of screening is also so dependent on satisfactory smears that quality assurance measures should be extended to include an assessment of the quality of the smears reported by laboratories according to the guidelines of the British Society for Clinical Cytology.

Laboratories should identify sources of poor smears and liaise with smear takers to ensure an improvement in smear quality.

We are grateful to all the General Practitioners, gynaecologists, histopathologists and radiotherapists who provided access to records or submitted cervical smears.

1 Koss LG. The Papanicolaou test for cervical cancer detection; a triumph and a tragedy. $\mathscr{F} A M A 1989 ; 261: 737-43$. tion; a triumph and a tragedy. $\mathcal{F} A M A 1989 ; 261: 737-43$.
Attwood ME, Woodman CBJ, Luesley D, Jordan JA Previous cytology in patients with invasive carcinoma of Previous cytology in patients with invasive
the cervix. Acta Cytol 1985;29:108-10.

3 Patterson MEL, Peel KR, Joslin CAF. Cervical smear histories of 500 women with invasive cervical cancer in Yorkshire. Br Med f 1984;289:896-8.

4 Robertson JH, Woodend B. The changing pattern of cervical cancer in Northern Ireland 1965-89. Ulst Med $\mathcal{f}$ 1992;61:19-23.

5 Baker A, Melcher DH. Rapid cervical cytology screening. Cytopathology 1991;2:299-301.

6 Bosch MMC, Rietweld-Scheffers PEM, Boon M Characteristics of false negative smears tested in the normal screening situation. Acta Cytol 1992;36:711-6.

7 Boon ME, Tabbers-Boumeester ML. "Histological" Boon ME, Tabbers-Boumeester ML. "Histological"
cytology. In: Gynaecological cytology. London: Macmillan Press, 1980:66.

8 Ayer BS, Pacey NF, Greenberg ML. The cytological features of invasive adenocarcinoma of the cervix uteri Cytopathology 1991;2:181-91.

9 Rylander E. Negative smears in women developing invasive cervical cancer. Acta Obstet Gynaecol Scand 1977; 56:115-8. 